\title{
Adult pancreatic $\beta$-cells are formed by self-duplication rather than stem-cell differentiation
}

\author{
Yuval Dor, Juliana Brown, Olga I. Martinez \& Douglas A. Melton
}

Department of Molecular and Cellular Biology and Howard Hughes Medical Institute, Harvard University, 7 Divinity Avenue, Cambridge, Massachusetts 02138, USA

How tissues generate and maintain the correct number of cells is a fundamental problem in biology. In principle, tissue turnover can occur by the differentiation of stem cells, as is well documented for blood, skin and intestine, or by the duplication of existing differentiated cells. Recent work on adult stem cells has highlighted their potential contribution to organ maintenance and repair. However, the extent to which stem cells actually participate in these processes in vivo is not clear. Here we introduce a method for genetic lineage tracing to determine the contribution of stem cells to a tissue of interest. We focus on pancreatic $\beta$-cells, whose postnatal origins remain controversial. Our analysis shows that pre-existing $\beta$-cells, rather than pluripotent stem cells, are the major source of new $\beta$-cells during adult life and after pancreatectomy in mice. These results suggest that terminally differentiated $\beta$-cells retain a significant proliferative capacity in vivo and cast doubt on the idea that adult stem cells have a significant role in $\beta$-cell replenishment.

The literature on pancreatic $\beta$-cells and islets of Langerhans is replete with studies suggesting various mechanisms for $\beta$-cell homeostasis and regenerative repair. Early studies on patterns of $\left[{ }^{3} \mathrm{H}\right]$ thymidine incorporation indicated that adult pancreatic endocrine cells belong to a class of tissues that could be maintained by the self-duplication of differentiated cells $^{1-3}$. More recent immunohistochemical observations suggest a stem-cell origin for islet cells, including insulin-expressing $\beta$-cells ${ }^{4}$. It has been proposed that these adult pancreatic stem or progenitor cells reside in the epithelium of pancreatic ducts ${ }^{5,6}$, inside islets ${ }^{7}$ or in the bone marrow $^{8}$. Others have suggested that $\beta$-cells form in the adult by transdifferentiation of pancreatic acinar cells ${ }^{9}$, islet cells that express hormones other than insulin ${ }^{10}$, or splenocytes ${ }^{11}$. In addition to explaining the formation of new $\beta$-cells within existing islets, it has also been suggested that whole new islets form (islet neogenesis) by clustering of new $\beta$-cells that are derived from stem cells ${ }^{5,12,13}$. However, all of these models and suggestions are, for the most part, based on the interpretation of static histological data rather than direct lineage analysis ${ }^{14}$.

We developed a simple method for distinguishing stem-cellderived $\beta$-cells from the progeny of pre-existing $\beta$-cells. Fully differentiated $\beta$-cells, defined here as post-natal cells transcribing the insulin gene, are heritably labelled in transgenic mice with a tamoxifen-inducible Cre/lox system ('pulse'). The label is the expression of the human alkaline phosphatase protein, which can be detected by a histochemical stain. After a long period, during which turnover occurs ('chase'), $\beta$-cells are examined for the presence of the label. Cells generated after the pulse are labelled if and only if they are the progeny of pre-existing (labelled) $\beta$-cells; new $\beta$-cells derived from any non- $\beta$ source, including stem cells, are not labelled. Different models of $\beta$-cell dynamics have distinct predictions regarding the frequency and distribution of labelled $\beta$-cells within pancreatic islets after a chase period (Fig. 1a). New islets derived entirely from stem or progenitor cells-that is, cells not yet transcribing the insulin gene-would not contain labelled $\beta$-cells. In addition, if stem cells replenish $\beta$-cells within existing islets, the frequency of labelled $\beta$-cells should gradually decrease. By contrast, if new $\beta$-cells are derived by self-duplication, the frequency of labelled $\beta$-cells within islets should remain constant.
We generated a transgenic mouse strain in which the insulin promoter ${ }^{15}$ drives the expression of tamoxifen-dependent Cre recombinase $^{16}$ (RIP-CreER). In this strain, the Cre-oestrogenreceptor (ER) fusion gene is expressed only in pancreatic $\beta$-cells, but the CreER protein is excluded from the cell nucleus. Tamoxifen injection results in a rapid and transient (about $48 \mathrm{~h}$ (ref. 17)) nuclear translocation of the CreER protein, which permits Cremediated recombination. As a readout for Cre activity we used a reporter strain $(\mathrm{Z} / \mathrm{AP})^{18}$ in which Cre-mediated removal of a stop sequence results in the constitutive and heritable expression of the gene encoding human placental alkaline phosphatase (HPAP) (Fig. 1b). Thus, a pulse of tamoxifen to bigenic RIP-CreER;Z/AP mice leads to HPAP expression in insulin-expressing cells present at the time of injection, as well as their progeny.

Control experiments with RIP-CreER;Z/AP mice were per- a

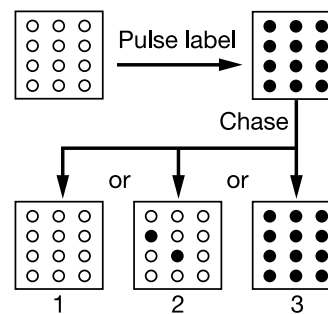

b

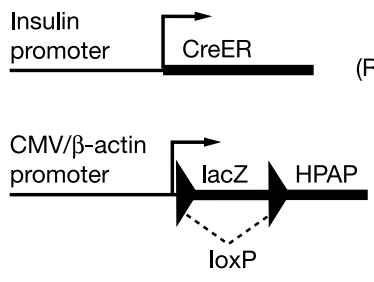

(RIP-CreER)

(Z/AP)

Figure 1 A pulse-chase system for determining the origin of $\beta$-cells. $\mathbf{a}$, Predictions from different models of $\beta$-cell maintenance. Squares represent islets; open and filled circles represent unlabelled and labelled $\left(\mathrm{HPAP}^{+}\right) \beta$-cells, respectively. In this example, the initial labelling efficiency of $\beta$-cells is $100 \%$. After a chase period, entirely stem-cell-derived new islets would contain no labelled cells (model 1). Within existing islets, maintenance by stem cells predicts a gradual decrease in the fraction of labelled $\beta$-cells (model 2), whereas maintenance by self-duplication predicts that the fraction of labelled $\beta$-cells remains constant (model 3). b, Transgenic mice. Tamoxifen injection of RIP-CreER;Z/AP bigenic mice results in a transient nuclear translocation of CreER, leading to removal of the loxP-flanked lacZ (serving as a stop sequence) and the permanent, heritable expression of the HPAP reporter gene. CMV, cytomegalovirus. 
formed to assess the specificity of labelling after tamoxifen injection. $\mathrm{HPAP}^{+}$cells are found only within islets (Fig. 2a); ducts, acini and blood vessels are not labelled (Fig. 2a). Double immunofluorescent analysis confirmed that ductal and acinar cells (detected by the DBA (Dolichos biflorus agglutinin) lectin and expressing amylase, respectively) do not express HPAP (Fig. 2c). Within islets, every $\mathrm{HPAP}^{+}$ cell $(n>1,000)$ expresses insulin (Fig. 2b). Non- $\beta$ islet cells (those expressing glucagon, somatostatin or pancreatic polypeptide) were all $\mathrm{HPAP}^{-}$, as would be expected from an insulin-promoter-driven transgene (Fig. 2c). The frequency of $\mathrm{HPAP}^{+}$cells depended on the tamoxifen dose (Fig. 2d). Thus, tamoxifen injection leads to a highly specific labelling of only differentiated $\beta$-cells (cells transcribing the insulin gene and positive for insulin by immunohistochemistry).

We injected tamoxifen into 24 RIP-CreER;Z/AP mice at 6-8 weeks of age, using a protocol (five injections of $4 \mathrm{mg}$ tamoxi- fen) that resulted in HPAP expression in about $30 \%$ of $\beta$-cells. Eight mice were killed 2 days after the last injection (the pulse group) and the remaining 16 mice were killed $2.5(n=1), 4(n=2), 6(n=5)$, $9(n=4)$ or $12(n=4)$ months later (the chase groups). Note that the 12-month time point represents about one-half of a mouse's lifespan. Sections of the pancreas were stained for insulin to identify $\beta$-cells and for HPAP to identify the cells that transcribed the insulin gene at time 0 (the pulse) and their daughters (see Fig. 1).

\section{No new islets are formed during adult life}

To identify whether entirely new islets were generated during the chase period, we compared the number of islets that contained labelled $\beta$-cells in the pulse and chase. Islets derived from stem cells (cells not expressing insulin at the time of pulse) would be completely $\mathrm{HPAP}^{-}$in the chase pancreases. All islets analysed a
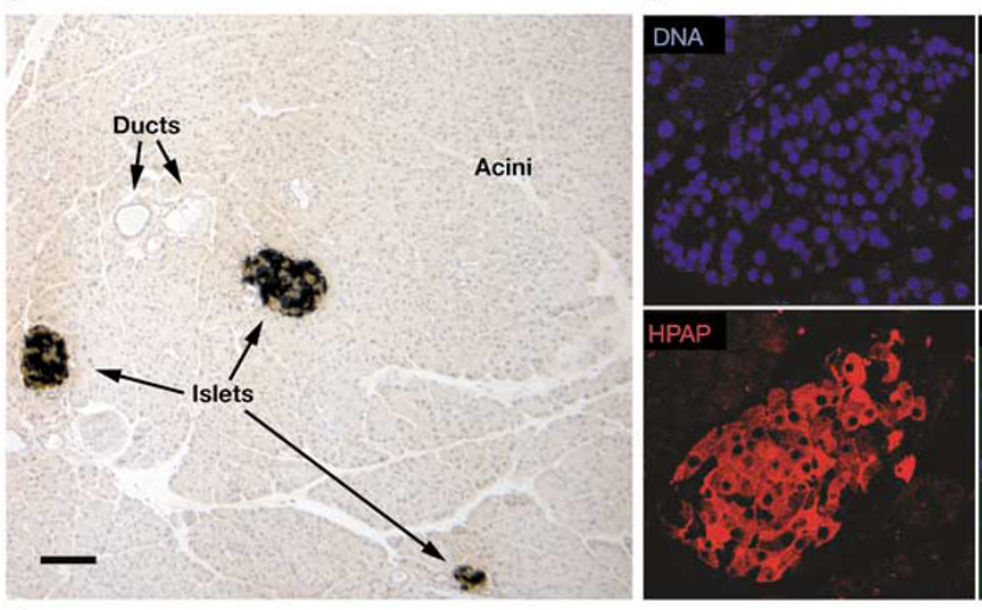
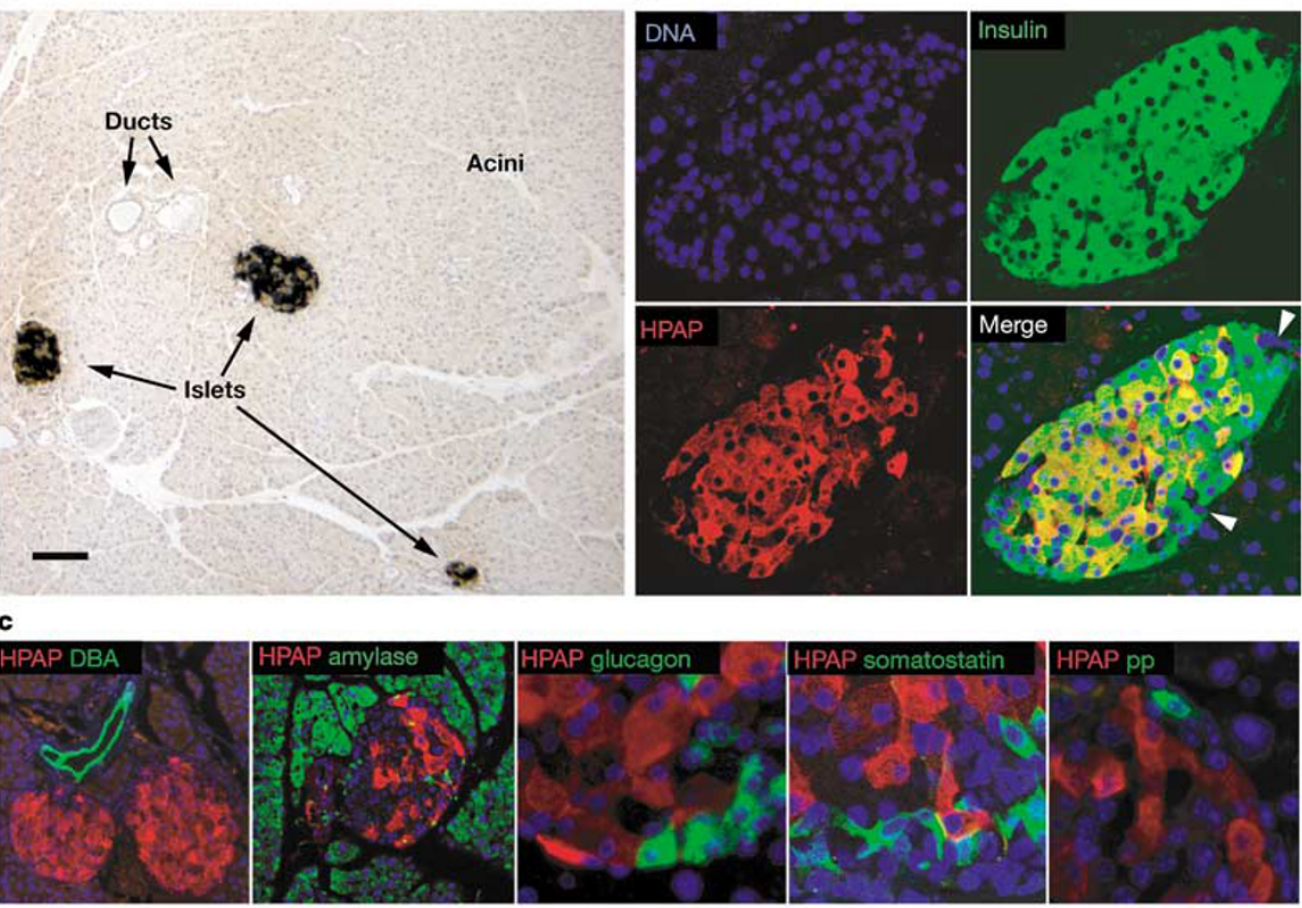

d

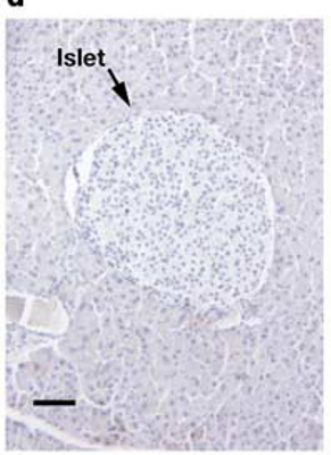

No TM

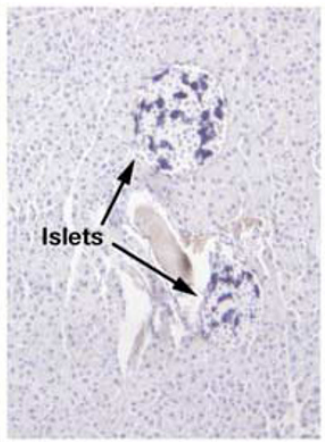

$1 \times 2 \mathrm{mg}$ TM
Figure 2 Specificity and dose dependence of recombination. a, HPAP expression is specific to islets. A section from the pancreas of a RIP-CreER;Z/AP mouse injected with tamoxifen 2 days before sacrifice and stained for insulin (brown) and HPAP (blue). HPAP cells are found in islets and are absent from acini and ducts. Original magnification, $\times 50$. Scale bar, $100 \mu \mathrm{m}$. Note that co-staining for insulin and HPAP results in a dark blue to black colour. b, HPAP labelling within islets is specific to $\beta$-cells. A confocal image of a section similar to a, stained for DNA (4,6-diamidino-2-phenylindole (DAPI); blue), insulin (green) and HPAP (red). All HPAP ${ }^{+}$cells also express insulin (orange in the lower-right

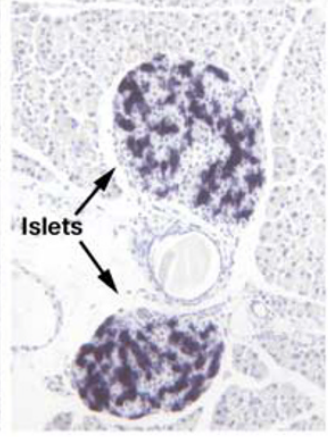

$1 \times 6 \mathrm{mg} \mathrm{TM}$

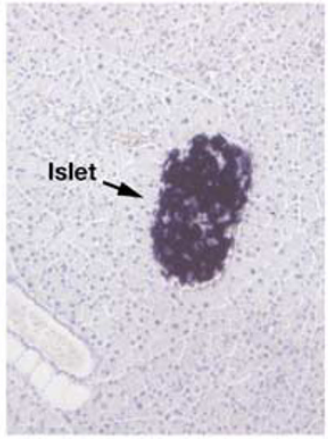

$5 \times 8 \mathrm{mg} \mathrm{TM}$ panel). Note that insulin-negative islet cells (for example, glucagon-positive cells) do not express HPAP (arrowheads). Original magnification, $\times 400$. c, $\mathrm{HPAP}^{+}$cells (red) do not express non- $\beta$-cell markers (green). DNA is stained with DAPI (blue). Original magnification for the DBA and amylase staining, $\times 200$; for the glucagon, somatostatin and pp staining, $\times 400$. $\mathbf{d}$, The degree of HPAP labelling in islets is dependent on the dose of tamoxifen (TM). Shown are sections of the pancreas from adult RIP-CreER;Z/AP mice, injected with the indicated dose of tamoxifen. Slides were stained for HPAP (dark blue) and counterstained with haematoxylin. Original magnification, $\times 100$. Scale bar, $50 \mu \mathrm{m}$. 

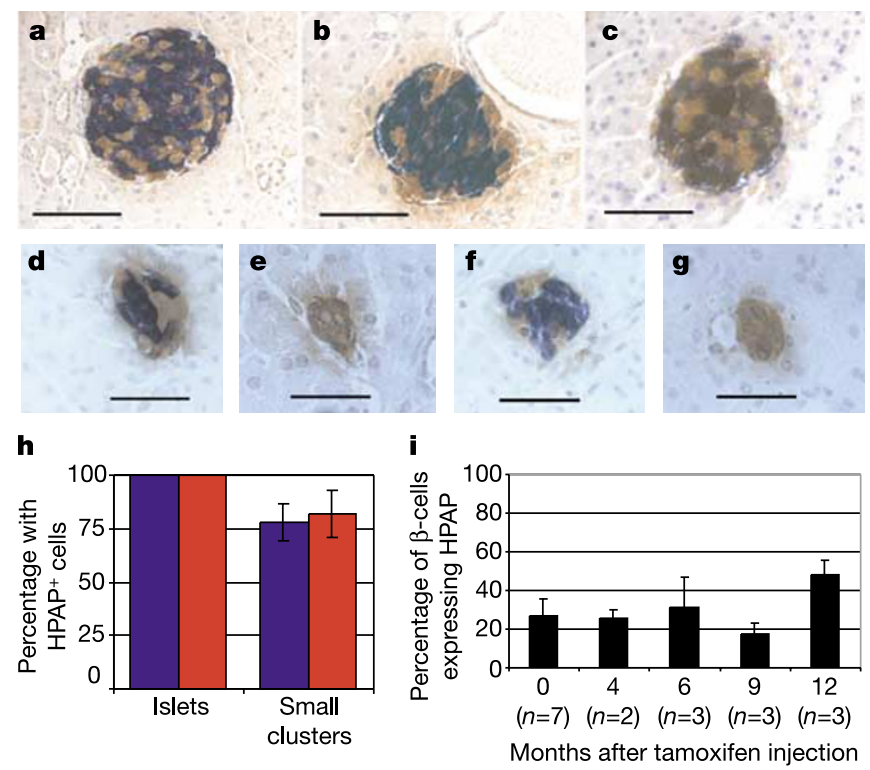

Figure 3 Analysis of islets and $\beta$-cells in pulse-chase experiments. $\mathbf{a}-\mathbf{g}$, Staining for HPAP (dark blue) and insulin (brown). a-c, Typical islets from mice killed immediately after tamoxifen injection (a), 4 months later $(\mathbf{b})$ or 1 year later $(\mathbf{c})$. Note that the HPAP stain obscures the brown insulin stain in double-positive cells. $\mathbf{d}-\mathbf{g}, \mathrm{HPAP}^{+}$and $\mathrm{HPAP}^{-}$ clusters of $\beta$-cells from mice immediately after the pulse $(\mathbf{d}, \mathbf{e})$ and in mice after a 6 month chase $(\mathbf{f}, \mathbf{g})$. Shown are clusters containing HPAP ${ }^{+} \beta$-cells $(\mathbf{d}, \mathbf{f})$ and clusters containing only unlabelled $\beta$-cells $(\mathbf{e}, \mathbf{g})$. Original magnification, $\times 400$. Scale bars, $50 \mu \mathrm{m}(\mathbf{a}-\mathbf{c})$, $25 \mu \mathrm{m}(\mathbf{d}-\mathbf{g})$. $\mathbf{h}$, Graph summarizing the frequency of HPAP ${ }^{+}$islets and small clusters (containing fewer than $10 \beta$-cells) in pulse-chase experiments with normal adult mice. Error bars represent standard deviations for all animals analysed ( $n=8$ for pulse, $n=16$ for all chase experiments combined). Blue, pulse; red, chase. i, Graph summarizing the frequency of $\beta$-cells expressing HPAP in adult RIP-CreER;Z/AP mice after tamoxifen injection. Bars represent the average percentage of $\mathrm{HPAP}^{+} \beta$-cells per mouse. Error bars represent standard deviations for all animals analysed for that time point; $n$ is the number of mice.

( $n=485$ for the pulse group, $n=744$ for the chase group; islet defined as a group of more than $10 \beta$-cells) contained numerous $\mathrm{HPAP}^{+} \beta$-cells. The finding that all islets in the chased mice contained $\beta$-cells that were present at the time of tamoxifen injection (or the progeny of such cells; Fig. 3a-c, h) suggests that no new islets are formed by stem or progenitor cells during adult life.

Given this unexpected result we extended our analysis to small, scattered clusters of 1-10 $\beta$-cells. The cells in these structures are often interpreted as newly formed, stem-cell-derived $\beta$-cells caught in the process of coalescing into larger or mature islets ${ }^{9,19-23}$. Such a model predicts that clusters found after a long chase should contain only $\mathrm{HPAP}^{-}$cells. In the pulse group, $77.8 \pm 8.4 \%$ of the small clusters analysed $(n=1,268)$ contained $\mathrm{HPAP}^{+} \beta$-cells, a frequency that was expected given the small size of the clusters and the efficiency of tamoxifen-dependent labelling. In the chase group, $81.8 \pm 10.9 \%$ of the clusters analysed $(n=1,423)$ contained HPAP $^{+} \beta$-cells (Fig. $3 \mathrm{~d}-\mathrm{h}$ ). Thus, there was no evidence that new clusters are generated from non- $\beta$-cells over the course of 12 months. We conclude, contrary to the commonly held view, that small clusters of $\beta$-cells do not represent stem-cell-derived islets. Rather, they might represent static mini-islets and/or disintegrating old islets. Taken together, these results point to the conclusion that no new islets are formed by stem or progenitor cells during adult life in the mouse (ruling out model 1 in Fig. 1a). The islets present in an old or middle-aged mouse are derived from islets that were present in 'teenage life' (2 months of age).

\section{$\beta$-cells are formed by self-duplication of pre-existing $\beta$-cells}

We next analysed these mice at the level of single cells, as opposed to islets, to examine $\beta$-cell maintenance. Sections of pulse and chase pancreases were stained for HPAP and insulin by double immunofluorescence, and scored for the percentage of $\beta$-cells that expressed $\mathrm{HPAP}^{+}$. The percentage of labelled $\beta$-cells, representing pre-existing $\beta$-cells or their progeny, remained stable in the chased mice (pulse, $4,759 \beta$-cells counted from 7 mice, $27.4 \% \mathrm{HPAP}^{+}$; chase, 8,988 $\beta$-cells counted from 11 mice, 29.54\% $\mathrm{HPAP}^{+}$). Even 12 months after the pulse there was no indication of dilution of the labelled population (Fig. 3i). This result suggests that within established islets, $\beta$-cells are either post-mitotic (see below) or derive from the replication of pre-existing $\beta$-cells. The results are not consistent with $\beta$-cells forming from stem or progenitor cells (ruling out model 2 in Fig. 1a).

A trivial explanation to these results would be that very little $\beta$-cell turnover occurred during the chase. In such a model, new stem-cell-derived $\beta$-cells, even though $\mathrm{HPAP}^{-}$, might escape detection because of their low rate of formation. On the contrary, fluorescence-activated cell sorting analysis of dissociated mouse pancreases shows that the absolute number of $\beta$-cells increases about 6.5 -fold between 3 and 12 months of age $\left((3.3 \pm 0.87) \times 10^{5}\right.$ for 3-month-old mice, $n=5$; $(2.2 \pm 0.9) \times 10^{6}$ for 10-12-monthold mice, $n=4$ ) (Fig. 4). This means that at least $85 \%$ of $\beta$-cells present at 12 months of age were formed during the previous 9 months. Taking into account a conservative estimation of $t_{1 / 2}=3$ months for adult rodent $\beta$-cells ${ }^{13}$, we estimate that $98 \%$ of $\beta$-cells

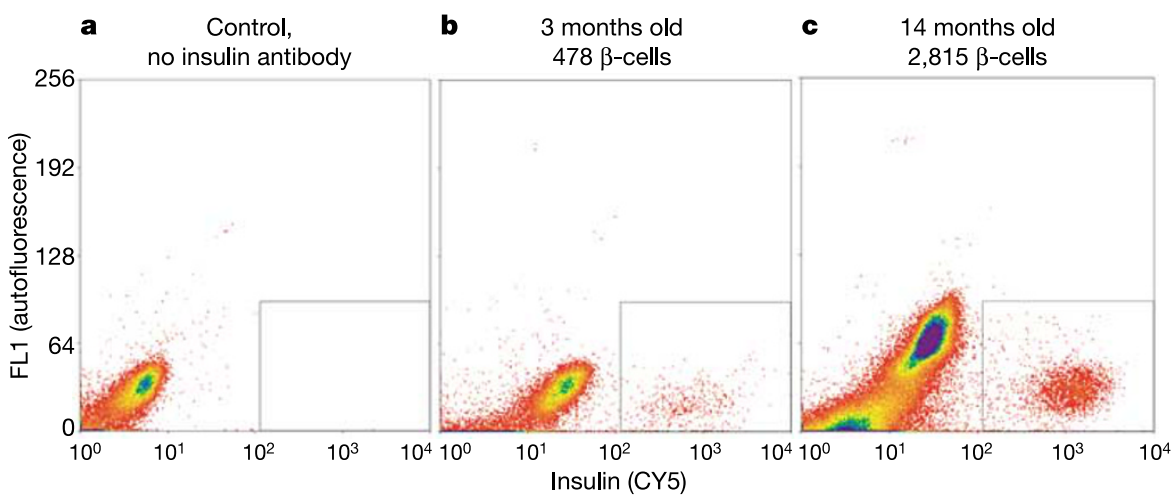

Figure 4 Total number of $\beta$-cells increases with age. Representative flow cytometric analysis of dissociated mouse pancreases stained for insulin expression. Shown are $0.1 \%$ of total pancreatic cells (a, b, 3-month-old nulliparous ICR female, 19,379 cells shown; c, 14-month-old nulliparous ICR female, 114,087 cells shown). a, № anti-insulin antibody added. The $x$ axis is CY5 fluorescence (reflecting insulin staining); the $y$ axis is autofluorescence. Insets, insulin-positive $\beta$-cells. 
present in an animal chased for 9 months were born after the pulse. A 'static' interpretation of the pulse-chase results is therefore untenable and we conclude that new $\beta$-cells are generated in the adult mouse primarily by the replication of pre-existing $\beta$-cells.

\section{$\beta$-cell regeneration}

Although the above experiments do not provide any evidence for the existence of stem or progenitor cells in the normal growth and maintenance of $\beta$-cells, it is possible that stem or progenitor cells do participate in other circumstances. For instance, an emerging concept in the field of adult stem cells is that of facultative stem cells, namely cells that acquire a stem cell character only after stimulation $^{24,25}$. In the pancreas, such cells have been proposed to reside in ducts, acini or inside islets ${ }^{4}$. After injury, these cells are thought to first proliferate, then differentiate into $\beta$-cells and migrate to form new islets or replenish existing islets. To test this idea we used partial pancreatectomy $(\mathrm{Px})$, an injury model in which regeneration has previously been documented ${ }^{4,5,12,26-29}$. We first verified that Px did indeed result in the generation of new $\beta$-cells. Bromodeoxyuridine (BrdU) was administered for 1 week to mice that had undergone partial (70\%) Px or had been sham operated. In agreement with previous reports ${ }^{5,26,27}$, Px mice had a higher frequency of BrdU incorporation in all pancreatic cells (islets, acini, ducts and blood vessels) than sham-operated mice. This included a 2.6-fold increase in the frequency of $\mathrm{BrdU}^{+} \beta$-cells after $\mathrm{Px}$, indicative of $\beta$-cell regeneration (12.3\% in Px versus $4.8 \%$ in shamoperated mice; $n=7,388$ and 5,311 $\beta$-cells, respectively; Fig. 5a).

We injected tamoxifen into adult RIP-CreER;Z/AP mice $(n=2)$, and 4 days later $70 \%$ of their pancreas was removed. The mice were killed 2 months after the operation; the remnant of the pancreas, as well as the previously excised and fixed portion, were stained for insulin and HPAP. All islets examined in the remnant portion $(n=126)$ and in the excised portion $(n=111)$ contained numerous $\mathrm{HPAP}^{+} \beta$-cells, showing that the islets found 2 months after Px existed before the operation. Furthermore, as observed during normal growth and adult life (Fig. 3), the frequency of clusters (groups of $1-10 \beta$-cells) containing $\mathrm{HPAP}^{+}$cells in the remnant portion $(87.3 \%, n=276)$ was similar to that in the excised portion $(85.5 \%, n=325)$, indicating that the clusters might not represent coalescing stem-cell-derived $\beta$-cells. These results suggest that, even after $\mathrm{Px}$, no new islets are generated from stem cells. Furthermore, the frequency of $\mathrm{HPAP}^{+} \beta$-cells within islets did not decrease after Px (data not shown), arguing against a significant contribution from non- $\beta$-cells or stem cells to the $\beta$-cells and islets found after pancreatectomy.

We wished to analyse directly the origin of new $\beta$-cells after Px, regardless of turnover rates or variations in labelling efficiency. To accomplish this we injected a high dose of tamoxifen (five injections of $8 \mathrm{mg}$ ) to another group of RIP-CreER;Z/AP mice $(n=5)$, and 14 days later performed $70 \%$ Px. BrdU was administered continuously for 2 weeks after the operation to label dividing cells, after which the mice were killed and their pancreases triple-stained for BrdU, insulin and HPAP (Fig. 5b). $\beta$-cells born after Px should express insulin and be $\mathrm{BrdU}^{+}$. If these new $\beta$-cells are derived from stem cells, they should be HPAP $^{-}$; if they are the product of $\beta$-cell self-duplication, they should be $\mathrm{HPAP}^{+}$. The data show that new $\beta$-cells were $\mathrm{HPAP}^{+}$in a frequency that precisely reflected the efficiency of recombination: 32 of $52(61.5 \%) \mathrm{BrdU}^{+} \beta$-cells were $\mathrm{HPAP}^{+}$; 266 of $436(61 \%)$ total $\beta$-cells counted were $\mathrm{HPAP}^{+}$. In other words, the results predict that if the labelling efficiency of $\beta$-cells were $100 \%$, all new $\beta$-cells would have been $\mathrm{HPAP}^{+}$; that is, they would have come from $\beta$-cells existing at the time of Px. It is theoretically possible that a putative 'stem cell' directly differentiates into a $\beta$-cell without cell division-that is, without BrdU incorporation. However, the absence of HPAP dilution in the chase experiments described above is inconsistent with such a process contributing significantly to $\beta$-cell number. This result further suggests that $\beta$-cells are derived from $\beta$-cells, not from stem cells.

\section{Discussion}

We conclude that pre-existing $\beta$-cells are the major source for new $\beta$-cells during adult life, as well as during regeneration from partial pancreatectomy (Fig. 1a, model 3). This conclusion challenges the view that adult stem cells (undifferentiated cells capable of selfrenewal and differentiation) are significant in $\beta$-cell homeostasis. Instead, we submit that terminally differentiated $\beta$-cells retain a proliferative capacity that can account for turnover and expansion throughout a mouse's life.
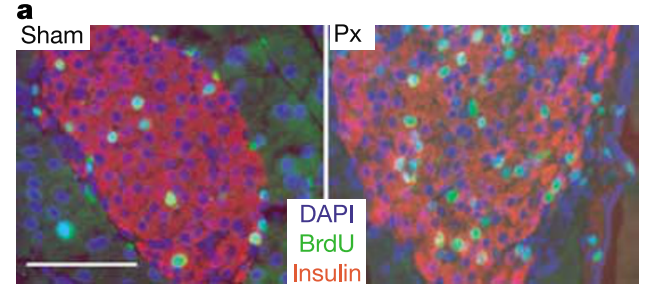

b
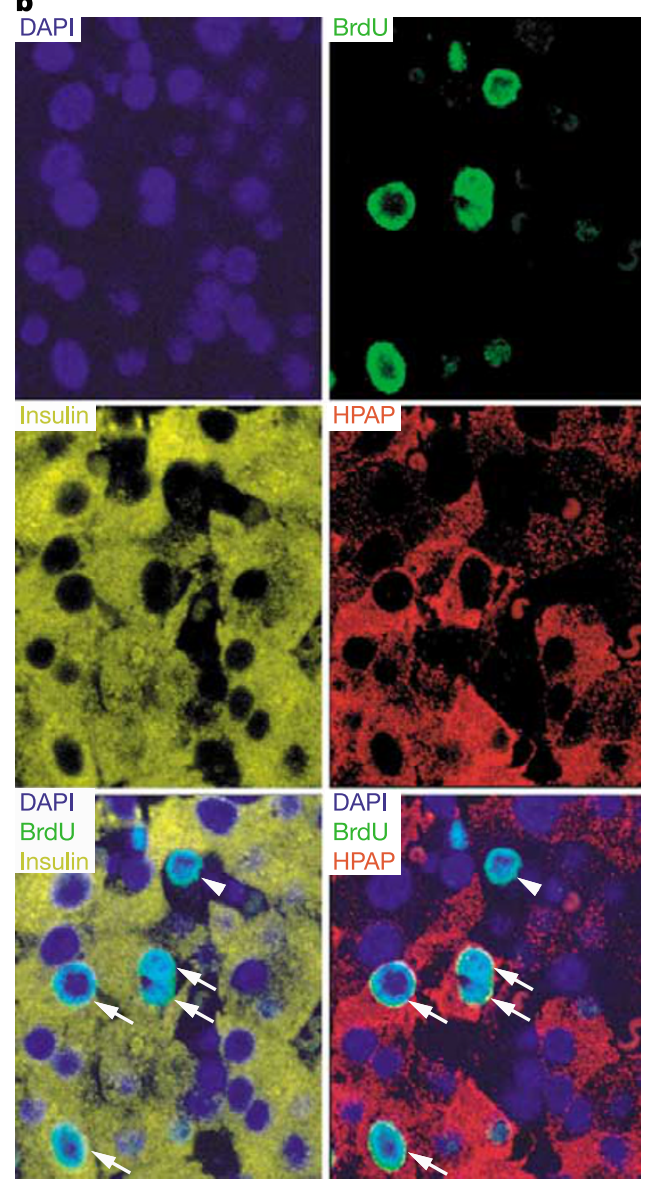

Figure 5 Analysis of $\beta$-cells after pancreatectomy. a, Increased BrdU incorporation after partial pancreatectomy (Px). Shown are representative islets from sham-operated or pancreatectomized mice, 7 days after operation. BrdU was administered continuously between operation and killing. Staining for BrdU (green), insulin (red) and DNA (blue). Original magnification, $\times 400$. Scale bar, $50 \mu \mathrm{m}$. b. Origins of new $\beta$-cells. Partial pancreatectomy was performed on tamoxifen-injected RIP-CreER;Z/AP mice, followed by BrdU administration for 2 weeks. Shown are confocal images of an islet stained for insulin (yellow), HPAP (red), BrdU (green) and DNA (blue). Four BrdU ${ }^{+} \beta$-cells are also $\mathrm{HPAP}^{+}$ (arrows), indicating that they were generated by replication of existing $\beta$-cells. One BrdU ${ }^{+}$ cell is insulin-negative and $\mathrm{HPAP}^{-}$(arrowhead); this is probably an $\alpha$ or $\delta$ cell. Original magnification, $\times 650$. 
There are several ways in which our data could be reconciled with previous reports claiming the existence of pancreatic stem cells. First, our experiments cannot prove the absence of stem cells, given the degree of variation in labelling efficiency inherent to the CreER system. It is possible that rare stem or progenitor cells exist but give rise to a small, physiologically unimportant fraction of $\beta$-cells ${ }^{17}$. A convincing demonstration of such putative stem cells could be provided by genetic lineage tracing, for example by using a duct cell promoter driving Cre recombinase. Second, it is formally possible that the insulin gene is transcriptionally active in stem cells. If so, these putative stem cells must be unipotent because $\mathrm{HPAP}^{+}$cells gave rise only to $\beta$-cells. Even after a long chase, no other endocrine, exocrine or ductal cells were $\mathrm{HPAP}^{+}$. In effect, such putative unipotent stem cells would be indistinguishable from $\beta$-cells. Third, facultative pancreatic stem cells might exist and be activated in response to specific insults other than pancreatectomy ${ }^{24,30}$. Fourth, the vast majority of $\mathrm{Px}$ and regeneration studies were done with rats rather than mice and it is possible that these species differ in the mode of regeneration. Last, $\beta$-cells could transiently dedifferentiate (and possibly acquire stem cell markers) before generating new $\beta$-cells ${ }^{12}$. A similar process is thought to occur during angiogenesis, in which differentiated endothelial cells give rise to 'activated endothelium', which then proliferates and organizes into new blood vessels ${ }^{31}$. However, there is currently no evidence for such a mechanism in the pancreas.

It has been suggested that new lobes, including new islets, are constantly generated in the adult pancreas ${ }^{13,32}$. In contrast, the data presented here support the idea that the number of islets during adult life is fixed, with homeostatic responses (for example, $\beta$-cell expansion) being performed by differentiated cells residing in these structural units. Indeed, it was recently reported that average islet size, but not islet density, increases with age ${ }^{33-35}$. Our studies indicate that there is a time during embryonic development, or early postnatal life, at which the number of islets is set. The data also indicate that $\beta$-cell formation from undifferentiated precursors ceases at this time in that new $\beta$-cells that form subsequently come from pre-existing $\beta$-cells. Further experiments are required to determine when this switch occurs.

Our results emphasize the importance of using direct lineage tracing, rather than histological snapshots, to determine a cell of origin or the provenance of a given tissue. The method presented here can be adapted to assess the contribution of stem cells in other organs during growth, normal turnover and regeneration. In addition, it could be used to determine the cell of origin in cancer models.

One implication of this study concerns possible cell-based therapies for type I diabetes, in which $\beta$-cells are destroyed by an autoimmune attack. It points to the significant proliferative potential of differentiated $\beta$-cells in vivo, a capacity that might be exploited for expansion to a clinically useful mass. In addition, the results highlight the fact that embryonic stem cells are currently the only type of stem cell that is unquestionably capable of differentiation into $\beta$-cells.

\section{Methods}

\section{Mice}

Z/AP reporter mice were a gift from C. Lobe ${ }^{18}$. The RIP-CreER construct was generated by fusing a 0.66 -kilobase SmaI-HindIII fragment of the RIP2 promoter ${ }^{15}$ to a minimal hsp68 promoter (a gift from M. Gannon ${ }^{36}$ ), and placing the chimaeric promoter upstream of CreER (a gift from A. McMahon ${ }^{16}$ ). Transgenic mice were created by injection of the construct into the pronucleus. Three founders were identified that, when crossed with Z/AP, showed $\beta$-cell-specific expression of HPAP (defined by immunohistochemical co-localization of HPAP and insulin). For this study we used two lines that showed efficient recombination. Both lines showed tamoxifen-dependent expression of HPAP. By 10 months of age, double transgenic mice that did not receive tamoxifen had occasionally one to five $\mathrm{HPAP}^{+}$cells per islet, reflecting the cumulative lifetime leakage of the system. RIP-CreER;Z/AP double transgenic mice were generated by crossing single heterozygous transgenics. Tamoxifen (Sigma) was dissolved in corn oil at $20 \mathrm{mg} \mathrm{ml}^{-1}$ and injected intraperitoneally or subcutaneously twice a week. RIP-CreER;Z/AP mice treated with tamoxifen remained euglycaemic and had normal pancreatic histology, indicating that tamoxifen injection, Cre-mediated recombination and HPAP expression had no adverse effects. For continuous labelling of dividing cells, BrdU (Sigma) was given in the drinking water at $0.8 \mathrm{mg} \mathrm{ml}^{-1}$, and the water was changed every other day.

\section{Analysis}

Formalin-fixed, paraffin-embedded $6-\mu \mathrm{m}$ sections of the pancreas were used. We identified $\beta$-cells by immunostaining for insulin (guinea-pig anti-insulin (Dako), dilution 1:500) or for pdxl (guinea-pig anti-pdx1 (a gift from C. Wright), dilution 1:500). Other pancreatic cell types were identified with the following antibodies: guinea-pig antiglucagon (Linco; dilution 1:200), sheep anti-somatostatin (ARP; dilution 1:200), guinea-pig anti-pancreatic polypeptide (Linco; dilution 1:200) and rabbit anti-amylase (Sigma; dilution 1:200). Ducts were labelled with biotinylated DBA lectin (vector; dilution 1:200). $\mathrm{HPAP}^{+}$cells were identified by incubating slides with alkaline phosphatase substrate as described ${ }^{17,18}$ or by immunostaining (rabbit anti-HPAP (Zymed), dilution 1:100, or goat anti-HPAP (Santa Cruz), dilution 1:100). $\mathrm{BrdU}^{+}$cells were stained with biotinylated anti-BrdU antibodies (BrdU in-situ detection kit (Becton Dickinson), dilution 1:100). For both HPAP and BrdU immunostaining we performed antigen retrieval (Retrievagen A; Becton Dickinson) before incubation with primary antibody. Secondary antibodies conjugated with horseradish peroxidase, fluorescein isothiocyanate, rhodamine (Jackson) or CY5 (Molecular Probes) were used at 1:200 dilution. Flow cytometry was carried out with MoFlo (Cytomation). Pancreases were dissociated to a single-cell suspension essentially as described ${ }^{37,38}$ and cells were stained with guinea-pig anti-insulin antibody followed by a CY5-conjugated anti-guinea-pig antibody.

Received 30 December 2003; accepted 29 March 2004; doi:10.1038/nature02520.

1. Messier, B. \& Leblond, C. P. Cell proliferation and migration as revealed by radioautography after injection of thymidine- $\mathrm{H}^{3}$ into male rats and mice. Am. J. Anat. 106, 247-285 (1960).

2. Leblond, C. P. in International Symposium on the Control of Cell Division and the Induction of Cancer (ed. Congdon, C. C.) 119-150 (Natl Cancer Inst., Bethesda, Maryland, 1964).

3. Tsubouchi, S., Kano, E. \& Suzuki, H. Demonstration of expanding cell populations in mouse pancreatic acini and islets. Anat. Rec. 218, 111-115 (1987).

4. Bonner-Weir, S. \& Sharma, A. Pancreatic stem cells. J. Pathol. 197, 519-526 (2002).

5. Bonner-Weir, S., Baxter, L. A., Schuppin, G. T. \& Smith, F. E. A second pathway for regeneration of adult exocrine and endocrine pancreas. A possible recapitulation of embryonic development. Diabetes 42, 1715-1720 (1993).

6. Zajicek, G., Arber, N., Schwartz-Arad, D. \& Ariel, I. Streaming pancreas: islet cell kinetics. Diabetes Res. 13, 121-125 (1990).

7. Zulewski, H. et al. Multipotential nestin-positive stem cells isolated from adult pancreatic islets differentiate ex vivo into pancreatic endocrine, exocrine, and hepatic phenotypes. Diabetes 50, 521-533 (2001).

8. Ianus, A., Holz, G. G., Theise, N. D. \& Hussain, M. A. In vivo derivation of glucose-competent pancreatic endocrine cells from bone marrow without evidence of cell fusion. J. Clin. Invest. 111, 843-850 (2003).

9. Lipsett, M. \& Finegood, D. T. Beta-cell neogenesis during prolonged hyperglycemia in rats. Diabetes 51, 1834-1841 (2002)

10. Guz, Y., Nasir, I. \& Teitelman, G. Regeneration of pancreatic beta cells from intra-islet precursor cells in an experimental model of diabetes. Endocrinology 142, 4956-4968 (2001).

11. Kodama, S., Kuhtreiber, W., Fujimura, S., Dale, E. A. \& Faustman, D. L. Islet regeneration during the reversal of autoimmune diabetes in NOD mice. Science 302, 1223-1227 (2003).

12. Bonner-Weir, S. Life and death of the pancreatic beta cells. Trends Endocrinol. Metab. 11, 375-378 (2000)

13. Finegood, D. T., Scaglia, L. \& Bonner-Weir, S. Dynamics of beta-cell mass in the growing rat pancreas. Estimation with a simple mathematical model. Diabetes 44, 249-256 (1995).

14. Slack, J. M. Developmental biology of the pancreas. Development 121, 1569-1580 (1995).

15. Hanahan, D. Heritable formation of pancreatic beta-cell tumours in transgenic mice expressing recombinant insulin/simian virus 40 oncogenes. Nature 315, 115-122 (1985).

16. Danielian, P. S., Muccino, D., Rowitch, D. H., Michael, S. K. \& McMahon, A. P. Modification of gene activity in mouse embryos in utero by a tamoxifen-inducible form of Cre recombinase. Curr. Biol. 8, 1323-1326 (1998).

17. Gu, G., Dubauskaite, J. \& Melton, D. A. Direct evidence for the pancreatic lineage: NGN3+ cells are islet progenitors and are distinct from duct progenitors. Development 129, 2447-2457 (2002)

18. Lobe, C. G. et al. Z/AP, a double reporter for cre-mediated recombination. Dev. Biol. 208, 281-292 (1999)

19. Wang, R. N., Kloppel, G. \& Bouwens, L. Duct- to islet-cell differentiation and islet growth in the pancreas of duct-ligated adult rats. Diabetologia 38, 1405-1411 (1995).

20. Yamamoto, K. et al. Recombinant human betacellulin promotes the neogenesis of beta-cells and ameliorates glucose intolerance in mice with diabetes induced by selective alloxan perfusion. Diabetes 49, 2021-2027 (2000).

21. Waguri, M. et al. Demonstration of two different processes of beta-cell regeneration in a new diabetic mouse model induced by selective perfusion of alloxan. Diabetes 46, 1281-1290 (1997).

22. Paris, M., Bernard-Kargar, C., Berthault, M. F., Bouwens, L. \& Ktorza, A. Specific and combined effects of insulin and glucose on functional pancreatic beta-cell mass in vivo in adult rats. Endocrinology 144, $2717-2727$ (2003).

23. Rooman, I., Lardon, J. \& Bouwens, L. Gastrin stimulates beta-cell neogenesis and increases islet mass from transdifferentiated but not from normal exocrine pancreas tissue. Diabetes 51, 686-690 (2002).

24. Alison, M. R. Liver regeneration with reference to stem cells. Semin. Cell Dev. Biol. 13, 385-387 (2002).

25. Oh, S. H., Hatch, H. M. \& Petersen, B. E. Hepatic oval 'stem' cell in liver regeneration. Semin. Cell Dev. Biol. 13, 405-409 (2002).

26. Liu, Y. Q., Montanya, E. \& Leahy, J. L. Increased islet DNA synthesis and glucose-derived lipid and amino acid production in association with beta-cell hyperproliferation in normoglycaemic $60 \%$ pancreatectomy rats. Diabetologia 44, 1026-1033 (2001)

27. Fong, I., Hulinsky, I., Fortuna, R. \& Silink, M. Mitotic activity and DNA synthesis of rat islet cells 


\section{articles}

following partial pancreatectomy. Pancreas 7, 453-459 (1992).

28. Finegood, D. T., Weir, G. C. \& Bonner-Weir, S. Prior streptozotocin treatment does not inhibit pancreas regeneration after 90\% pancreatectomy in rats. Am. J. Physiol. 276, E822-E827 (1999).

29. Hardikar, A. A., Karandikar, M. S. \& Bhonde, R. R. Effect of partial pancreatectomy on diabetic status in BALB/c mice. J. Endocrinol. 162, 189-195 (1999).

30. Fausto, N. \& Campbell, J. S. The role of hepatocytes and oval cells in liver regeneration and repopulation. Mech. Dev. 120, 117-130 (2003).

31. Carmeliet, P. Angiogenesis in health and disease. Nature Med. 9, 653-660 (2003).

32. Bunnag, S. C. Postnatal neogenesis of islets of Langerhans in the mouse. Diabetes 15, 480-491 (1966).

33. Kushner, J. A. et al. Pdxl restores beta cell function in Irs2 knockout mice. J. Clin. Invest. 109, 1193-1201 (2002)

34. Skau, M., Pakkenberg, B., Buschard, K. \& Bock, T. Linear correlation between the total islet mass and the volume-weighted mean islet volume. Diabetes 50, 1763-1770 (2001).

35. Bock, T., Pakkenberg, B. \& Buschard, K. Increased islet volume but unchanged islet number in $o b / o b$ mice. Diabetes 52, 1716-1722 (2003).

36. Wu, K. L. et al. Hepatocyte nuclear factor $3 \beta$ is involved in pancreatic beta-cell-specific transcription of the pdx-1 gene. Mol. Cell. Biol. 17, 6002-6013 (1997).
37. Freshney, R. I. Culture of Animal Cells: A Manual of Basic Technique (Wiley-Liss, New York, 2000)

38. Arkle, S., Lee, C. M., Cullen, M. J. \& Argent, B. E. Isolation of ducts from the pancreas of copperdeficient rats. Q. J. Exp. Physiol. 71, 249-265 (1986).

Acknowledgements We thank J. Dubauskaite for zygote injection, G. Kenty for help with fluorescence-activated cell sorting analysis, $\mathrm{H}$. Hsieh for technical assistance, and S. Bonner-Weir, A. Regev and members of the Melton laboratory for discussions. D.A.M. is a Howard Hughes Medical Institute Investigator. Y.D. was supported by EMBO and JDRF postdoctoral fellowships.

Competing interests statement The authors declare that they have no competing financial interests.

Correspondence and requests for materials should be addressed to D.M.

(dmelton@mcb.harvard.edu). 